\title{
Book Review: The Routledge Companion to Organizational Diversity Research
}

\section{Methods}

My former PhD supervisor and I were recently discussing the role of a 'companion' as a promising metaphor. A companion is someone with you on your journey with whom to share the experience, a witness of your encounters and reflections. Research is often a solitary journey on which postgraduate students would certainly appreciate such company, if student feedback on their experience is anything to go by. Researching diversity is a demanding endeavour: it spans deeply personal issues of identity as well as pressing social issues of equality and change. In this context relatability for students is as important as the need to be relevant by solving diversity issues in the workplace. The quality of a companion should therefore include such criteria: does it provide compelling conversations on diversity discourse and does it speak about research practice in ways which students find useful. In this sense Just, Risberg, and Villasèche's (2021) collection The Routledge Companion to Organizational Diversity Research Methods is an enriching and thought-provoking companion.

The collection opens with the need to problematise the purpose behind diversity research. We are made aware of the different approaches to understanding and improving diversity practices developing over time: defining categories of diversity, who gets to write the narratives of diversity experience through privileged positions, diversity management as an organisational asset, fluidity of identity and bias with a focus on individualised experiences etc. These raise important questions for research students, a much-needed opportunity to 
enliven the methodology discussions in class and even to resolve conceptual confusions (particularly around "ologies"). What problems is diversity research meant to be solving? What methods do these approaches and objectives call for? The companion goes some way to address these and raises others in the process. Is the goal of diversity research aligned with management goals to reducing inequality as part of the company's social responsibility commitments? Or is it about harnessing identity experiences within the workplace for positive employee outcomes? Should researchers be bound to particular diversity agendas by wider societal goals?

The companion sets out to explore different designs and knowhow on diversity research delineating categories of difference (race, ethnicity, gender, sexual orientation, disability, tenure), research methods used, workplace settings by industry and geography. The editors present the works as a collective call for a careful consideration of the researcher's own subject position, the location, role and delineations of the researched by the researcher. It thus gives a prominent place to reflexivity and the role of the researcher in the research process including their potential as activists (Just et al. 2021). I find this particularly valuable to the research students, who often only read the results of published research and miss out the detailed account of the process of getting there - the challenges, interpretations and junctures along the way, including recognising their own assumptions, biases, and objectives.

Part I introduces a number of concepts relevant to enquiring about who has the right to tell the stories of diversity experiences and how these stories can be told: the white observer, embodied critique, commodifying difference, racial comfort, etc. Holck and Muhr provide an 
enriching reflexivity angle and detailed account of what it feels like to do ethnographic research as white researchers on whiteness and postcolonialism in a Greenlandic Police Force work context, a former Danish colony. The detail in note taking with parallel voices (conversations of those observed, the voice of the researchers' embodied experience of being in the field) and their significance are useful lessons in qualitative fieldwork in a racially charged context. Interestingly, this chapter points to the role of humour in negotiating identity and diversity, joining earlier research on humour as agency for change, resistance, or hegemony (see for example humour and boundaries of ethnic difference in blue collar context by Wise 2016 , etc.). In a socially mediated context increasingly sensitive to what is and isn't acceptable humour in the social presentation of self (not to mention the 'cancel culture' phenomenon), this is a relatable context for new generation researchers. A postcolonial research context is also relevant for many international students who in my experience are looking for insights into the mechanisms by which they and their organisation can become change agents.

Two other relevant chapters found later on in Doing Field Work are Dorion's work on feminist epistemology and Burchiellaro's experience of researching LGBT friendliness. Dorion's chapter is the only place we encounter how social movements and feminist ethnography inform diversity research; Burchiellaro unpicks the multi-sidedness of researcher identity in exploring diversity practices in LGBT-friendly corporate London context whilst holding activist credentials. The chapters reveal the personal experience of conducting activist research and offer reflections on the significance of generating knowledge through ethnographic, embodied research whilst owning one's sexual identity as integral to the research process. It would have been even more insightful for these 
researchers to include examples of how such tensions in identity translate into data interpretation. Students need to see the discursive move from experiencing fieldwork to writing up the findings, beyond 'identifying themes' which they are typically instructed to do. The relative importance of some themes over others, the selection of particular fieldwork experiences as "telling" are issues which originate from precisely such tensions. How identity tensions affect write-up gives way to an even more important question - how can we study and understand the role of identity in the workplace more broadly? This is potentially explosive as it ventures into 'identity politics'.

Students will no doubt see these reflexivity chapters as an invitation to reflect on their verging identities, on their research projects as possibilities for an authentic experience, on their potential activist agency in seeking to address inequality in the workplace. This is not removed from dealing with identity politics, on which notion the Stanford Encyclopaedia of Philosophy observes "There is no real identity[...] that is separable from its conditions of possibility, and any political appeal to identity formations must engage with the paradox of acting from the very subject-positions it must also oppose" (Heyes 2020: 15). This point resonates with a popular topic with HRM postgraduate students in my organisational theory course: the paradox of embedded agency and institutional entrepreneurship, where students are advised that (identity-forming) social position is of utmost importance for change (e.g. Battilana 2006).

Chapter 6 moves on boldly from the researcher experience and onto diversity-in-practice. Christensen's discussion on normalising heterosexuality in the workplace tackles how people speak about what is 'normal' in the workplace. Findings here suggest sexual 
orientation is seen by some groups as a non-professional matter which should stay out of the workplace, which may prevent free expression of identity, this view being shared mostly by heterosexual norm setters. On a methodological point, students might want to consider the extent to which explicit organisational commitments to diversity reflect the underlying values and even cultural norms in the workplace. As a dissertation supervisor I constantly see students assuming that asking "what is going on" and taking responses at face value is sufficient.

Christensen's findings complement earlier research (e.g. Priola et al. 2014) which reports that despite a formal commitments to inclusivity in organisations, "discriminatory practices such as silence, gossip and derogatory comments are common and described as normal, [leading to] denial of both the importance of sexual orientation in the workplace and the discrimination that LGBT employees are subjected to" (Priola et al. 2014.:22). Furthermore, the chapter raises the broader question how much individuals should disclose about their identity in the workplace, beyond sexuality. What should we be asking ourselves (and data) when peeling back workplace identity from other strands of one's identity? I find HRM students to be intrigued by these questions and expect they' $d$ find Christensen's chapter particularly insightful.

The Inclusive Research section tackles the challenge of defining, observing, and measuring diversity, and asks how to make it more inclusive. The national diversity chapter defends the need to distinguish heterogeneity from inequality, challenging the temptation to equate heterogeneity to diversity. It calls instead on considering types of variety within diversity, where variety across income levels can become a diversity measure (Paunova). Essentially a 
paper on 'defining for measuring diversity', it could be very useful in a discussion on how to operationalise research variables. Aidley and Fearon's disability chapter points out that people with disabilities are excluded from research by researchers who fail to make accommodating modifications to their methods. Gloor et al. review a selection of experimental manipulations used to investigate various forms of diversity in different settings. It lists a variety of issues which researchers may be unaware of when applying tools to measure diversity in the field.

Interestingly, the dominant approach to studying diversity with a single category inherently implies that "scholars overlook how belonging to multiple categories may alter a person's identity and experience, as well as how they are perceived by others" (Gloor et al.: 101). A section on intersectionality would have been useful here (as acknowledged in the guide's conclusion). Many postgraduate students are aware of the concept of intersectionality and could have benefited from more examples on how to tackle it in practice. For example, Tatli and Özbilgin (2012) use Bourdieu to propose emerging diversity categories as having greater potential for exploring intersectionality, and bring attention to "relations of power in all their different manifestations at work"(Tati and Özbilgin 2012: 181). Their work is cited in Kutscher who looks at a social class perspective to diversity, using cluster analysis of cultural capital structure in Austria as context. She explains how variables are selected for cultural capital analysis from an existing survey data set and related to work conditions and diversity. The implications section unfortunately is quite brief.

The section From Data to Analysis provokes thoughts about how research quality and choice of methods should be introduced to students in light of managing their expectations. A 
lecturer using the textbook to highlight choice of methods and researcher roles could find examples of each. The text may not be as valuable to a student using it to understand to what extent academia builds successfully on diversity research to solve diversity challenges in practice.

The last chapter by Buzzanell and Fine stands out with its two cases of applying qualitative causal analysis. They discuss the value of this qualitative approach, how "linguistic markers can indicate causality in qualitative inquiry, and how the method [...] reveal[s] the intricate processes through which marginalization, privilege, and exclusion-inclusion dynamics are reinforced"; how it can make visible that which is implied and tacit in understanding what is happening from marginalised positions (Buzzanell and Fine 2021: 245). Causal analysis can be insightful when studying complex phenomena, the relationship between interrelated factors and the attributed meanings attributed. The authors present a case of an India/US call-centre context, where power-resistance dialectics can be revealed through Indian workers' microresistance and sensemaking strategies embodied in their conversational interactions with American customers (ibid.). It certainly alerts readers to the potential of qualitative methodology beyond interviews and thematic analysis.

In the same section the chapters on videography (Skoglund), gender, board memberships, and power elite mapping using network analysis (Villesèche et al.), and researching business celebrity autobiographies (Adamson) are examples that research can be used in creative ways, with methods beyond interviews and surveys. It also hints to a future of diversity research where the challenge is harnessing an ever-accelerating digital production and 
consumption of data. Therefore it would have been helpful to see more examples of handson experience on managing complex data in the companion.

In conclusion, l've sensed a frustration by students regarding the extent to which academic diversity conversations have caught up with practice. Questions include why is management research so slow to catch up with public conversations? Or why focus exclusively on gender when discussing diversity in leadership and bias? Where are the activist approaches in researching inclusion and voice in the workplace (in management research), beyond tracing whether inclusion strategies officially appear as company policies? The Routledge companion on diversity research methods does a decent job in addressing at least some of these questions. More importantly, it fills some of the gaps in postgraduate research methods training, at the same time staying relevant to burgeoning organisation studies themes and resonating with student concerns. The most exciting parts are those where contributors manage to draw back the curtain to reveal what diversity fieldwork really looks and feels like, and why it is so personal and difficult to do. 
Battilana, J (2006) Agency and institutions: The enabling role of individuals' social position. Organization, 13(5): 653-676.

Heyes, C (2020) Identity Politics, The Stanford Encyclopedia of Philosophy Edward N.

Zalta (ed.) Available at: www.plato.stanford.edu/archives/fall2020/entries/identity-politics (accessed 10 June 2021)

Priola, V, Lasio, D, De Simone, S and Serri, F (2014) The sound of silence. Lesbian, gay, bisexual and transgender discrimination in 'inclusive organizations'. British Journal of Management, 25(3): 488-502.

Tatli, A and Özbilgin, MF (2012) An emic approach to intersectional study of diversity at work: a Bourdieuan framing. International Journal of Management Reviews, 14(2): 180-200.

Wise, A. (2016). Convivial labour and the 'joking relationship': Humour and everyday multiculturalism at work. Journal of Intercultural Studies, 37(5): 481-500. 